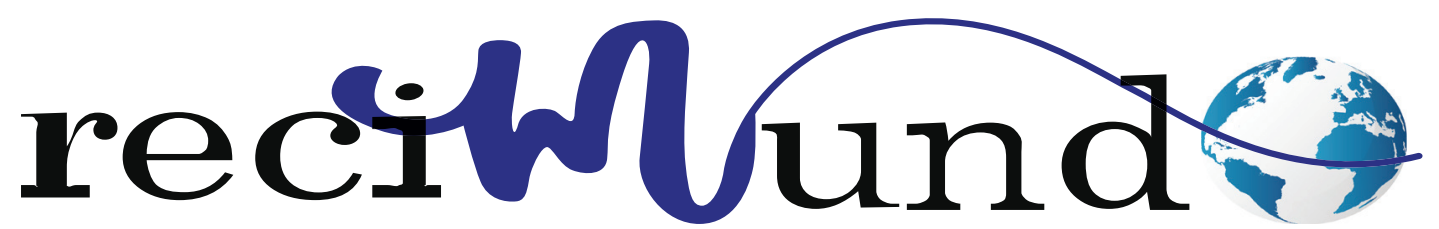

Revista Científica Mundo de la Investigación y el Conocimiento

DOl: 10.26820/recimundo/5.(4).oct.2021.84-95

URL: https://recimundo.com/index.php/es/article/view/1301

EDITORIAL: Saberes del Conocimiento

REVISTA: RECIMUNDO

ISSN: 2588-073X

TIPO DE INVESTIGACIÓN: Artículo de revisión

Código UNESCO: 32 Ciencias Médicas

PAGINAS: 84-95

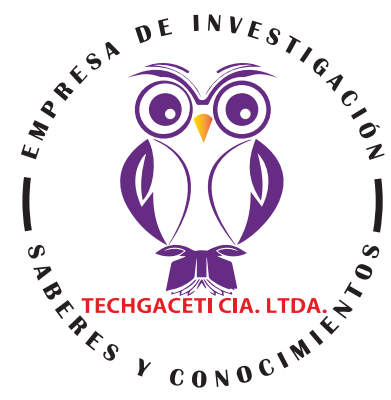

\title{
Transmisión perinatal por COVID-19 en América Latina
} Perinatal transmission by COVID-19 in Latin America Transmissão perinatal por COVID-19 na América Latina Isabel Odila Grijalva Grijalva'; Humberto Miguel Marengo Gallardo²; Dennisse Isabel Parreño Grijalva³; Rosa María Bulgarín Sánchez ${ }^{4}$

RECIBIDO: 02/09/2021 ACEPTADO: 20/09/2021 PUBLICADO: 30/10/2021

1. Doctora en Medicina y Cirugía de la Universidad de Guayaquil; Magister en Salud Pública de la Universidad de Guayaquil; PhD. estudiante en Ciencias de la Salud de la Universidad de Granada-España; Docente Titular de la Universidad Santiago de Guayaquil - Facultad de Ciencias Médicas; Ecuador; isabel.grijalva@cu.ucsg.edu.ec; (D) https://orcid.org/0000-00034491-4149

2. Doctor en Medicina y Cirugía de la Universidad Católica de Santiago de Guayaquil; Especialista en Ginecología y Obstetricia de la Universidad de Guayaquil; Ecuador; Docente de la Universidad Católica Santiago de Guayaquil - Facultad de Ciencias Médicas; humberto.marengo@cu.ucsg.edu.ec; (D) https://orcid.org/0000-0001-5331-4693

3. Médico de la Universidad Católica de Santiago de Guayaquil; Investigador Independiente; Guayaquil, Ecuador; dennisseparreno@gmail.com; (iD https://orcid.org/0000-0003-1243-3834

4. Doctora en Medicina y Cirugía de la Universidad de Guayaquil; Magister en Gerencia en Servicios de la Salud; Docente Titular de la Universidad Santiago de Guayaquil; Ecuador; rosa.bulgarin@cu.ucsg.edu.ec; iD https://orcid.org/0000-00017933-0253

\section{CORRESPONDENCIA}

Isabel Odila Grijalva Grijalva

isabel.grijalva@cu.ucsg.edu.ec

Guayaquil, Ecuador 


\section{RESUMEN}

La salud materno infantil contiene una carga emotiva especial desarrollada empáticamente por el ser humano. Dada la declaración de pandemia por la OMS durante el 2020 resulta oportuno estudiar lo efectos de ella sobre las poblaciones vulnerables, entre las que se destacan las mujeres gestantes y con ella, los aun nonatos Se ha de realizar un bosquejo de las publicaciones digitales científicas académicas a través del motor de búsqueda Google y su par académico Scholar Google del cual se escogen las publicaciones más relevantes de acuerdo con el objetivo planteado, descartando las publicaciones sobre estudios específicos de gestantes y tomando, en dado caso, solamente las discusiones y conclusiones de dichos estudio según previo análisis y resumen de los aportes abonados a la comunidad académica. Por estar el tema relacionado a la pandemia provocada por el virus SARS-Cov-2, no se establecen criterios de exclusión de tiempo pues escasamente los estudios al respecto no datan de 2 años a partir de la fecha de esta investigación, sin embargo se consideran publicaciones de los organismos internacionales como OMS, UNICEF, UN en cuanto a los convenios y tratados pertinentes para el tema. Entre los hallazgos bibliográficos no se encuentra ninguno que termine de verificar o rechazar la existencia de COVID-19 perinatal, más en América Latina. Ha sido posible la verificación de información sobre los efectos del COVID-19 en gestantes y algunas consecuencias posiblemente atribuibles a la enfermedad, pero hasta el momento tampoco son concluyentes. Esta situación era de alguna manera esperable dado el tiempo en el que ha venido transcurriendo la enfermedad, el COVID-19 de alguna manera nos ha tomado desprevenidos, más si se le suma la situación sanitaria con la que cuenta la mayoría de las poblaciones latinoamericanas, donde las condiciones para brindar salud pública resultan precarias o insuficientes.

Palabras clave: COVID-19, Perinatal, Gestación, pandemia, comorbilidad.

\section{ABSTRACT}

Maternal and child health contains a special emotional charge developed empathically by the human being. Given the declaration of a pandemic by the WHO during 2020, it is appropriate to study the effects of it on vulnerable populations, among which pregnant women stand out and with it, the still unborn An outline of academic scientific digital publications has to be made Through the search engine Google and its academic peer Scholar Google, from which the most relevant publications are chosen according to the objective set, discarding publications on specific studies of pregnant women and taking, where appropriate, only the discussions and conclusions of said study according to previous analysis and summary of contributions paid to the academic community. Since the issue is related to the pandemic caused by the SARS-Cov-2 virus, no time exclusion criteria are established since studies in this regard do not date back 2 years from the date of this research, however they are considered publications of international organizations such as WHO, UNICEF, UN regarding the relevant conventions and treaties on the subject. Among the bibliographic findings there is none that has finished verifying or rejecting the existence of perinatal COVID-19, especially in Latin America. Verification of information on the effects of COVID-19 in pregnant women and some consequences possibly attributable to the disease has been possible, but so far they are not conclusive either. This situation was in some way expected given the time in which the disease has been passing, COVID-19 has somehow caught us off guard, more if we add the health situation that most Latin American populations have, where the conditions to provide public health are precarious or insufficient.

Keywords: COVID-19, Perinatal, Gestation, pandemic, comorbidity.

\section{RESUMO}

A saúde materno-infantil contém uma carga emocional especial desenvolvida de forma empática pelo ser humano. Dada a declaração de uma pandemia pela OMS em 2020, é oportuno estudar os efeitos dela nas populações vulneráveis, entre as quais se destacam as gestantes e com ela os nascituros. o motor de busca Google e o seu congénere académico Google, a partir do qual são seleccionadas as publicações mais relevantes de acordo com o objectivo definido, descartando as publicações sobre estudos específicos de mulheres grávidas e tomando, se for caso disso, apenas as discussões e conclusões do referido estudo de acordo com o anterior análise e síntese das contribuições pagas à comunidade acadêmica. Por se tratar de uma questão relacionada à pandemia causada pelo vírus SARS-Cov-2, não foram estabelecidos critérios de exclusão temporal, uma vez que os estudos a esse respeito não datam de 2 anos a partir da data desta pesquisa, porém são considerados publicações de organismos internacionais como a OMS, UNICEF, ONU em relação às convenções e tratados relevantes sobre o assunto. Dentre os achados bibliográficos, não há nenhum que tenha terminado de verificar ou rejeitar a existência de COVID-19 perinatal, especialmente na América Latina. Foi possível verificar as informações sobre os efeitos do COVID-19 em mulheres grávidas e algumas consequências possivelmente atribuíveis à doença, mas até agora também não são conclusivas. Esta situação era de alguma forma esperada dado o tempo em que a doença foi passando, a COVID-19 de alguma forma nos pegou desprevenidos, mais se somarmos a situação de saúde que vive grande parte das populações latino-americanas, onde as condições de atendimento à saúde pública são precária ou insuficiente.

Palavras-chave: COVID-19, Perinatal, Gestação, pandemia, comorbidade. 


\section{Introducción}

La salud materno infantil contiene una carga emotiva especial desarrollada empáticamente por el ser humano. Supone en la madre un sacrificio de su salud para darle vida a un nuevo ser, por tanto se cuidan dos vidas en un solo cuerpo.

En 2013 se celebró en Johannesburgo (Sudáfrica) la primera conferencia mundial sobre la salud del recién nacido, en respuesta a la creciente constatación de que los Objetivos de Desarrollo del Milenio no se ocupaban específicamente de la supervivencia o la salud de los recién nacidos o de la prevención de la mortinatalidad, que, por consiguiente, recibían menos atención e inversiones. A fin de que esa tendencia no persistiera en la era de los ODS, se celebró una consulta mundial para elaborar el plan de acción «Todos los recién nacidos». La atención a la madre y el recién nacido de calidad es un servicio de salud esencial que debe mantenerse para proteger la vida y la salud de las mujeres y los niños. Este servicio esencial debe reforzarse, de manera que pueda resistir ante las crisis, como la de la COVID-19, y permita avanzar hacia los objetivos mundiales acordados en materia de salud maternoinfantil. (WHO/ MCA/OMS, 2020)

Un nuevo enfoque utilizado en algunos países de ingresos altos es establecer la relación entre las afecciones maternas y las perinatales para abordar mejor los obstáculos en materia de atención que afectan tanto a la madre como al recién nacido. La elaboración de The WHO application of ICD-10 to deaths during the perinatal period: ICD-PM tiene por objeto asociar las muertes prenatales y neonatales a afecciones maternas concomitantes, cuando proceda, de forma uniforme en todos los contextos. Esto ayudará a normalizar y aumentar la información sobre las causas de defunción en torno al momento crítico del parto. El proceso para determinar la causa de defunción en el contexto de una auditoría de la mortalidad debería ser fácil de aplicar y comparable en todos los entornos, ser bien aceptado por los observadores, y dar lugar a un porcentaje elevado de casos clasificables y un porcentaje bajo de causas de defunción no explicadas. (Organización Mundial de la Salud, 2017)

Es evidente que las organizaciones mundiales has sumado esfuerzos para mejorar la situación en cuanto a la atención materno infantil, aún cuando no teníamos idea de la emergencia sanitaria que viviríamos con la llegada de la COVID-19. Uno de los esfuerzos radica en la medición real de las muertes perinatales o neonatales, desde una verificación de las causas puesto que la mayoría de esas vidas ni son registradas y mucho menos estudiadas.

Se sabe que el embarazo altera el sistema inmune del cuerpo y la respuesta a las infecciones virales en general, las que pueden en ocasiones causar síntomas más severos. Las gestantes con comorbilidades pueden tener mayor riesgo para enfermar gravemente, lo que es consistente con la población general con comorbilidades similares. Aun cuando en estos momentos existen pocos datos epidemiológicos de la enfermedad en neonatos (COVID-19) y menos aún de seguimiento de estos casos. (Pacheco Romero, 2020) Sin embargo la Red de la Sociedad Iberoamericana de Neonatología reportó que de 86 mujeres embarazadas con COVID-19, 6\% de los recién nacidos fueron prematuros, $7 \%$ dieron positivo al PCRrt, ninguno falleció, 76\% separó al binomio, en $95 \%$ de los casos la madre no pudo ser acompañada en el parto ni puerperio, solo $24 \%$ de las madres fueron autorizadas a amamantar. Esta es una realidad que grafica parte de las consecuencias de la pandemia en la atención neonatal (Aliaga, Marcos, Perez, \& Vivas, 2020, pág. 35). 
Con la presente investigación se pretende recopilar la información médica disponible que pueda establecer indicios de padecimiento perinatal de COVID-19.

\section{Metodología}

Se ha de realizar un bosquejo de las publicaciones digitales científicas académicas a través del motor de búsqueda Google y su par académico Scholar Google del cual se escogen las publicaciones más relevantes de acuerdo con el objetivo planteado, descartando las publicaciones sobre estudios específicos de gestantes y tomando, en dado caso, solamente las discusiones y conclusiones de dichos estudio según previo análisis y resumen de los aportes abonados a la comunidad académica.

Por estar el tema relacionado a la pandemia provocada por el virus SARS-Cov-2, no se establecen criterios de exclusión de tiempo pues escasamente los estudios al respecto no datan de 2 años a partir de la fecha de esta investigación, sin embargo se consideran publicaciones de los organismos internacionales como OMS, UNICEF; UN en cuanto a los convenios y tratados pertinentes para el tema.

\section{Resultados}

A inicios de marzo de 2021, estamos en la segunda oleada de la enfermedad causada por el virus SARS-CoV-2 y, entre los países más afectados actualmente por los contagios, después de Estados Unidos (cerca de 30 millones) figuran la India y Brasil, con 11 millones; Rusia y Reino Unido con 4 millones; Francia con cerca de 4 millones y España con 3 millones. En América Latina, Colombia, Argentina y México han superado los 2 millones de infecciones, mientras Perú está llegando al millón y medio. (Pacheco Romero, 2021)

El Colegio Americano de Obstetras y Ginecólogos (ACOG) aconseja que la mejor atención de las pacientes en esta pandemia de COVID-19 depende de los signos y síntomas de la paciente, sus comorbilidades, el problema médico de fondo, la agudeza de su presentación (condición aguda versus crónica), la disponibilidad de los recursos de salud y otros factores. Las visitas preventivas, despistajes de rutina, consejería y prescripción anticonceptiva, el quiste de ovario asintomático, el manejo de síntomas menopáusicos, los seguimientos ginecológicos o postoperatorios rutinarios, el cribado de salud mental o conductual pueden ser dirigidos por telesalud o diferidos para después del brote de COVID-19. Los procedimientos obstétricos y ginecológicos cuyo diferimiento pueda afectar la salud y la seguridad de la paciente, no deben sufrir retraso. (Pacheco Romero, 2020) Hallazgos estadísticos Covid -19 en gestantes, implicaciones perinatales y neonatos, mortalidad infantil, síntomas y tratamientos.

Un reciente artículo sueco señala que, entre 2.682 pacientes que se presentaron en trabajo de parto, el 5,8\% fueron positivas para el SARSCoV-2 (91\% al ingreso y $9 \%$ durante el embarazo). El $65 \%$ de las pruebas positivas fueron asintomáticas. Los síntomas por adaptación fisiológica al embarazo o eventos adversos de la gestación (p. ej. disnea, fiebre, síntomas gastrointestinales, fatiga) pueden solaparse a los de COVID-19. La mayoría de mujeres (85 a $86 \%$ ) con SARS-CoV-2 presentará enfermedad leve, la tasa de enfermedad severa varía entre 9,3 y $11,1 \%$, y aquellas con enfermedad crítica, entre 2 y $6,9 \%$, que son similares a los de la población general. (Pacheco Romero, 2020)

En una reciente revisión sistemática sobre la situación de COVID perinatal se identificaron 17 publicaciones, la mayoría de China. En estos estudios, en general series de casos, se reportaron datos de SARS-CoV-2 en $\mathrm{RN}$ de 214 mujeres embarazadas con infección sospechada o confirmada en el

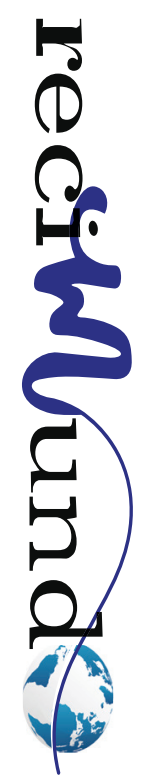


momento del nacimiento. En cuatro RN la RT-PCR para SARS-CoV-2 fue positiva en hisopados respiratorios obtenidos entre las 36 horas y los 8 días después del nacimiento. En esta revisión sistemática otros 3 estudios incluyeron 8 neonatos readmitidos positivos para SARS-CoV-2. La mayoría de los RN tuvo síntomas leves o nulos y no se informó ningún resultado perinatal adverso. En un estudio de Estados Unidos1se han descrito madres con COVID-19; un escaso número tuvo enfermedad severa o crítica, con porcentajes similares a los descriptos en mujeres no embarazadas, y sin COVID-19 en los RN. Otras revisiones reportaron baja morbilidad y nula mortalidad en madres de diferentes países, ninguna de ellas de América Latina. En una de ellas la tasa de cesáreas fue del 93\% en 287 casos y en ningún caso se mantuvo la lactancia. Algunos autores han señalado la necesidad de contar con redes de datos que generen evidencia, particularmente en América Latina, a fin de establecer pautas y recomendaciones definitivas adaptadas a la región. (Sola, Rodríguez, Cardetti, \& Dávila, 2020)

Un cribado rutinario en la ciudad de Nueva York para SARS-CoV-2 mediante RTPCR antes del parto identificó un $88 \%$ de gestantes asintomáticas, y los casos sintomáticos fueron leves. Similares resultados se reportaron en un estudio realizado en el INMP de Perú que aplicó pruebas rutinarias de serología para SARS-CoV-2. Un estudio multicéntrico en América Latina encontró $68 \%$ de madres infectadas asintomáticas, $89 \%$ de las madres sintomáticas presentaron sintomatología leve o moderada y el 2,3\% ingresaron a terapia intensiva. Estas diferencias porcentuales pueden deberse al tipo de estudio, tipo de prueba y diferencias en las poblaciones, a pesar de ello sugieren mayormente una elevada frecuencia de gestantes asintomáticas y concuerdan con el hallazgo de síntomas respiratorios leves. Sin embargo, existe variabilidad clínica en la madre, lo cual debe considerarse al momento de evaluar las condiciones del recién nacido. (Dávila Aliaga, y otros, 2021)

Las tasas de parto pretérmino de $20 \%$ y de cesáreas de $80 \%$ parecía que se relacionaban con patrones de práctica regionales. La tasa de muerte neonatal era 0,3\%. (Pacheco Romero, 2020)

Los principales signos y síntomas de 272 gestantes hospitalizadas con COVID-19 fueron fiebre/escalofríos, tos, dificultad para respirar, algias musculares, nausea/ vómitos, cefalea, dolor de garganta, dolor abdominal, dolor torácico; $16 \%$ requirieron ser admitidas a $\mathrm{UCI}, 8 \%$ a ventilación mecánica y $1 \%$ falleció. (Pacheco Romero, 2021)

448 de $458(97,8 \%)$ de las mujeres completaron sus gestaciones y tuvieron parto con niño vivo y 10 (2,2\%) perdieron el embarazo. (Pacheco Romero, 2020)

Si bien la pandemia de COVID-19 ha ocasionado una preocupación mundial respecto de las consecuencias de la infección viral en las mujeres embarazadas y los RN, en 86 mujeres embarazadas reportadas de 7 países de América Latina a la Red SIBEN no hubo fallecimientos y solamente 3,5\% presentó enfermedad severa. A diferencia de otras publicaciones, los casos presentados en este estudio corresponden a un registro multicéntrico prospectivo de varios países, y no a reportes de una sola institución ni a revisiones de casos de artículos publicados (Sola, Rodríguez, Cardetti, \& Dávila, 2020)

Se observó que el 11,3\% de los recién nacidos fueron prematuros y el 9,3\% presentó bajo peso al nacer. Sin embargo, se deben considerar los partos pretérminos iatrogénicos que llegan a alcanzar cifras del $80 \%$ de los partos, en donde el $48 \%$ se debió a infección materna de SARS-CoV-2, solo el $14 \%$ por compromiso fetal y el $18 \%$ por 
otras causas obstétricas. En el presente estudio la atención del parto obedeció a la condición obstétrica y no solo a la detección de infección por SARS-CoV-2. En el estudio no se encontraron muertes neonatales; no obstante, dos recién nacidos ingresaron a cuidados intensivos y cuatro a cuidados intermedios debido a comorbilidades perinatales, con prueba RT-PCR negativa. Una revisión sistemática encontró un índice de muerte perinatal del $7 \%$, otro estudio reportó una muerte entre 108 casos y una baja morbilidad. Los casos ingresados a cuidados intensivos o intermedios fueron los que requirieron mayor tiempo de hospitalización debido a prematuridad, dos casos de neumonía, sepsis, ictericia, acidosis metabólica y un caso de encefalopatía. Sin embargo, la mayoría de recién nacidos tuvieron un peso normal, incluido el caso de recién nacido con RT-PCR positiva, y fueron dados de alta dentro de los tres días de nacido sin complicaciones. Se observó solo un caso de recién nacido con RT-PCR positiva para SARS-CoV-2 dentro de las 12 horas de vida, lo cual podría sugerir una trasmisión vertical. Estudios previos han descrito que la trasmisión placentaria viral podría darse por vía hematógena. (Dávila Aliaga, y otros, 2021)

Algunos estudios, aunque no todos, han sugerido que los mortinatos se producen con mayor frecuencia entre las personas infectadas por el SARS-CoV-2 o durante la pandemia. Por ejemplo, en un análisis realizado en el Reino Unido, la tasa de mortinatos fue 2 a 3 veces mayor entre las embarazadas durante la pandemia que antes de ella, con tasas de 9,3 frente a 2,4/1000 nacimientos, respectivamente, aunque se desconoce si el aumento está relacionado con la infección por el SARS-CoV-2 o con otros factores relacionados con la pandemia. (Pacheco Romero, 2021)

\section{Comorbilidades asociadas a la compli- cación de gestantes con COVID-19}

Los CDC señalan que las prevalencias de obesidad pregestacional y diabetes gestacional fueron mayores en las gestantes hospitalizadas por problemas relacionados a COVID-19 (p.ej., empeoramiento del estatus respiratorio). En las madres infectadas y hospitalizadas por coronavirus COVID-19, más de 90\% con neumonía, el parto pretérmino fue el resultado obstétrico adverso más frecuente. La infección por COVID-19 también se asoció con preeclampsia, cesáreas y muerte perinatal. Entre las pacientes con síntomas leves al ingreso, todas las que dieron a luz por vía vaginal tuvieron excelentes resultados. Por contraste, $13,5 \%$ de las cesareadas tuvieron resultados maternos graves y $21,6 \%$ deterioro clínico. El parto por cesárea también se asoció con aumento del riesgo de admisión del neonato a la UCIN. (Pacheco Romero, 2020)

Entre las complicaciones obstétricas se encontraron rotura prematura de membranas $(18,6 \%)$ y preeclampsia $(11,6 \%)$ mientras que entre las comorbilidades de los recién nacidos se encontró prematuridad $(11,3 \%)$, bajo peso al nacer $(9,3 \%)$ y sepsis con neumonía que requirió ventilación mecánica (4,7\%). (Dávila Aliaga, y otros, 2021)

Según la publicación sueca, las pacientes que dieron positivo tuvieron más probabilidad de tener preeclampsia $(7,7 \%$ frente a $4,3 \%)$ y menos probabilidades de ser sometidas a inducción del trabajo de parto $(18,7 \%$ frente a $29,6 \%$ ). (Pacheco Romero, 2020)

Las principales complicaciones obstétricas observadas fueron rotura prematura de membranas y preeclampsia, similar a lo encontrado en estudios previos que utilizaron la prueba RT-PCR para la detección de SARS-CoV-2 así como en estudios que uti-

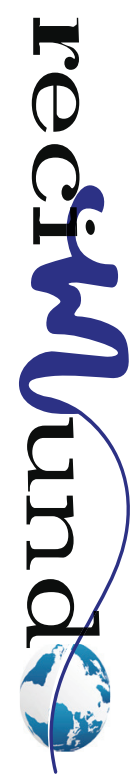


lizaron pruebas serológicas en gestantes. La frecuencia de preeclampsia observada en el presente estudio $(11,6 \%)$ estaría dentro de los hallazgos reportados en estudios previos a la pandemia por COVID-19, donde varían entre un $2 \%$ y $12 \%$. Sin embargo, la frecuencia de rotura prematura de membranas $(18,6 \%)$ es mayor a los hallazgos en la población antes de la pandemia por COVID-19, donde varía entre $8 \%$ al $10 \%$. No obstante, la variabilidad observada en las complicaciones puede corresponder a la carga viral durante el embarazo. Sin embargo, estos estudios son descriptivos, por lo cual, no cuentan con un análisis causal para apoyar un riesgo asociado a la infección por SARS-CoV-2. (Dávila Aliaga, y otros, 2021)

Las comorbilidades preexistentes, edad materna mayor e índice de masa corporal elevado, son factores de riesgo de COVID-19 severo. El Reino Unido ha publicado recientemente las características y resultados en gestantes admitidas al hospital con infección SARS-CoV. La edad gestacional media al momento de la admisión fue 34 semanas, 10\% requirieron $\mathrm{UCI}$ y 1,2\% falleció. (Sola, Rodríguez, Cardetti, \& Dávila, 2020)

En los partos, $75 \%$ fueron a término y $15 \%$ pretérmino ( $7 \%$ debido a complicaciones del COVID-19), 59\% tuvo cesárea, la mayoría por razones no relacionadas al COVID-19. Dos neonatos fallecieron y tres nacieron muertos, en quienes no fue clara la relación con la infección por SARS-CoV-2. La edad mayor de 35 años y la obesidad aumentaron el riesgo de hospitalización. La gestación parece haber empeorado el curso del COVID-19 en pacientes de habla hispana, quienes tuvieron mayor estadía en el hospital, mayor tasa de falla renal, sepsis, coagulación intravascular diseminada, uso de unidad de cuidados intensivos, ventilación mecánica y más letalidad. Parece que en varias regiones del Perú estuvieran aumentando el aborto, restricción del crecimiento intrauterino, parto pretérmino y la muerte fetal. (Pacheco Romero, 2020)

Se ha publicado que las gestantes con COVID-19 en los EE UU, atendidas entre el 22 de enero y el 1 de setiembre 2020, fueron 20.216, las muertes 44. La edad más frecuente fue entre 20 y 39 años, casi el doble en hispánicas o latinas que en las mujeres blancas, no hispánicas y de raza negra no hispánicas. (Pacheco Romero, 2020)

Se ha ido aprendiendo progresivamente sobre el cuidado general en adultos, pero no así sobre la COVID-19 en la mujer embarazada y el recién nacido $(\mathrm{RN})$. Por lo tanto, es necesario ser prudente al formular recomendaciones y evitar hacerlas sin evidencia firme. Esta evidencia está en construcción y plantea desafíos importantes para crear un ambiente seguro para los pacientes y los agentes de salud perinatal. (Sola, Rodríguez, Cardetti, \& Dávila, 2020) Entre 2019 y 2020, la mortalidad materna aumentó en 42,3\% (de 302 a 430 muertes maternas), siendo complicaciones los partos pretérmino, la preeclampsia. En las gestantes infectadas por SARS-CoV-2 y que desarrollaron neumonía, se ha presentado parto pretérmino, aborto, preeclampsia, muerte perinatal y/o indicación de cesárea pretérmino. (Pacheco Romero, 2021) Desde los primeros casos notificados de COVID-19 en las Américas hasta el 14 de enero de 2021, en 19 países/territorios de los que se disponía de información, hubo 139.016 casos positivos de SARS-CoV-2 en mujeres embarazadas, incluidas 802 muertes (1\%). En comparación con los datos de la Actualización Epidemiológica de la Organización Panamericana de la Salud/ Organización Mundial de la Salud (OPS/ OMS) del 11 de diciembre de 2020, esto representa un aumento de 18.065 casos nuevos y 105 muertes nuevas. Durante el mismo período, los mayores aumentos relativos de casos confirmados y muertes se observaron en Venezuela. Más de 40 mil 
embarazadas dieron positivo al virus y 76 fallecieron en el Perú. El cierre del primer nivel de atención fue un factor negativo clave, no habiéndosele dado prioridad en su reapertura. La OPS, en su actualización epidemiológica sobre COVID-19, señala que, por millón de habitantes, Perú es el primer país con más mujeres embarazadas con COVID-19 en América Latina. Nuestro país tiene al $49 \%$ de gestantes infectadas de la región. (Pacheco Romero, 2021)

Hasta el momento el SARS-CoV-2 ha causado pocos casos de COVID-19 en RN y mujeres embarazadas; en los casos reportados el cuadro clínico con frecuencia ha sido leve. Aunque existen publicaciones sobre COVID-19 en mujeres embarazadas y RN, todas informan experiencias en uno o dos centros, ninguna incluye un gran número de casos y ninguna proviene de América Latina. Hasta el momento los tratamientos en evaluación, como antivirales, corticosteroides, plasma de convaleciente o antiparasitarios, no han demostrado efectividad ni seguridad y por lo tanto no deberían ser empleados fuera de protocolos de investigación. Por otro lado, el uso de oxígeno durante el parto no solo es innecesario si la oximetría de pulso de la madre es normal, sino que puede generar riesgo de aerosolización y transmisión del virus a los profesionales de la salud y otros. (Sola, Rodríguez, Cardetti, \& Dávila, 2020) Aún no existe evidencia concluyente que permita establecer la existencia de transmisión vertical en el tercer trimestre. Son preocupantes los hallazgos que, en casi todos los casos, no se permitió que las madres tuvieran compañía. Además, es alarmante la muy baja tasa de lactancia materna y la frecuente separación de la díada madre-hijo. En la actualidad todas las sociedades científicas recomiendan que la determinación de separar temporalmente a una madre con COVID-19 de su RN debe hacerse caso por caso y en base a decisiones compartidas. Toda madre tiene derecho a estar con su RN y amamantarlo y en esa situación se aconseja usar estrictas medidas para reducir el riesgo de infección, como barreras físicas (distancia) y uso de máscara facial; cuando eligen amamantar, además, debe llevarse a cabo la higiene de manos y senos antes y después de cada alimentación. El impacto negativo de estas prácticas para el futuro de la madre y el niño merecerá próximos estudios, pero podrían tener consecuencias relevantes. La depresión posparto y los suicidios, y las disrupciones de las alteraciones vinculares y sus consecuencias ya eran una preocupación en el equipo de salud perinatal antes de la pandemia. (Sola, Rodríguez, Cardetti, \& Dávila, 2020)

Sin embargo, se han publicado reportes sobre la presencia de anticuerpos IgM elevados en el recién nacido, en las primeras horas posparto, lo que podría indicar que es posible la transmisión vertical del SARSCoV-2 (Limay Ríos, Dávila Aliaga, Álvarez Carrasco, \& Espinola Sánchez, 2020, pág. 297)

Para confirmar una trasmisión vertical se debe detectar el ARN viral en el cordón umbilical, la sangre neonatal en las primeras doce horas y la placenta o líquido amniótico antes de la ruptura de membranas. Existen reportes de casos de trasmisión placentaria mediante el estudio de muestras biológicas, en donde la madre y el recién nacido presentaron algún tipo de complicación. A pesar de la limitada evidencia sobre trasmisión vertical, se ha reportado que existe un $4 \%$ de incidencia de infección en el posparto y los recién nacidos con RT-PCR positivo con frecuencia son asintomáticos, según hallazgos de una revisión sistemática en base a reportes de casos. (Dávila Aliaga, y otros, 2021)

Durante el mes de abril 2020, se registraron 47 muestras de hisopado nasofaríngeo en neonatos, de hasta dos días de nacidos, cuyos resultados fueron negativos, a excepción de un caso cuya muestra fue

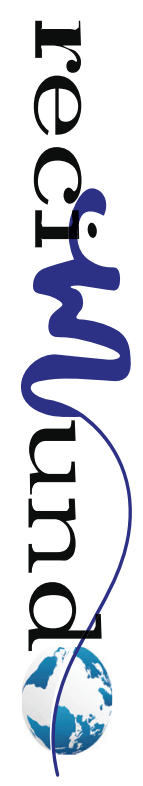


tomada al segundo día de vida, sin poder descartar una posible infección congénita, intraparto o posnatal. El caso del recién nacido con prueba molecular positiva presentó prueba serológica negativa para la infección por el SARS-CoV-2; mientras que, de los 46 recién nacidos con prueba molecular negativa, 17 presentaron anticuerpos de IgM positiva/lgG positiva y 5 presentaron solamente IgG positiva. Dado que la IgM es una macromolécula, la cual no atraviesa regularmente la placenta, se trataría de una respuesta neonatal, la cual podría corresponder a una infección congénita; sin embargo, debido a que la determinación de anticuerpos es por prueba rápida, es posible dar falsos positivos por otros virus y otras moléculas como hormonas; además, por ser un ensayo indirecto cualitativo no puede ser concluyente en el diagnóstico de una infección congénita. (Limay Ríos, Dávila Aliaga, Álvarez Carrasco, \& Espinola Sánchez, 2020)

Actualmente, la disponibilidad de exámenes diagnósticos en los tejidos mencionados es escasa. A pesar de que se han observado casos de neonatos con la presencia de IgM contra SARS-CoV-2, no es posible afirmar la existencia de una infección congénita basada solo con la detección de IgM, por lo que se requieren más estudios a partir de muestras de líquido amniótico, cordón umbilical o placenta. (Limay Ríos O. , Dávila Aliaga, Álvarez Carrasco, \& Espinola Sánchez, 2020)

Al momento, hay reportes de posible transmisión vertical de la madre al producto, la cual parece ocurrir en el tercer trimestre de gestación, sin poderse descartar el riesgo potencial y consecuente de morbimortalidad fetal. Un hospital israelí ha informado del caso de un feto de 36 semanas de gestación nacido muerto y portador del virus en una mujer infectada por el coronavirus; la infección intrauterina se habría producido a través de la placenta. Se trata del primer caso de este tipo notificado en Israel.
La mujer, de 29 años, en su $25^{\mathrm{a}}$ semana de embarazo, llegó al hospital tras dos días de fiebre y síntomas de COVID-19, al darse cuenta de que no había movimiento fetal. La mujer dio positivo en las pruebas de detección del coronavirus cuando ingresó al hospital y, en las pruebas realizadas al mortinato, se descubrió que el bebé era portador del virus. El jefe del Departamento de Enfermedades Infecciosas del Hospital Assuta de Ashdod (Israel) dijo que había pocos casos registrados en el mundo de una madre que infectara a un feto, algunos de los casos registrados en Brasil. (Pacheco Romero, 2021)

Otro caso de un feto que murió con complicaciones relacionadas con el COVID-19 había sido visto anteriormente en Israel. La infección neonatal por SARS-CoV-2 es poco frecuente en los bebés ingresados en el hospital. La infección con ingreso neonatal tras el nacimiento de una madre con infección perinatal por SARS-CoV-2 es poco probable. (Pacheco Romero, 2021)

\section{Conclusiones}

Entre los hallazgos bibliográficos no se encuentra ninguno que termine de verificar o rechazar la existencia de COVID-19 perinatal, más en América Latina. Ha sido posible la verificación de información sobre los efectos del COVID-19 en gestantes y algunas consecuencias posiblemente atribuibles a la enfermedad, pero hasta el momento tampoco son concluyentes.

Esta situación era de alguna manera esperable dado el tiempo en el que ha venido transcurriendo la enfermedad, el COVID-19 de alguna manera nos ha tomado desprevenidos, más si se le suma la situación sanitaria con la que cuenta la mayoría de las poblaciones latinoamerticanas, donde las condiciones para brindar salud pública resultan precarias o insuficientes. 
Al respecto, los investigadores apuntan a que "Hoy más que nunca resulta imperioso sostener recomendaciones específicas para asignar los recursos sanitarios de una manera justa, lo que incluye maximizar los beneficios de las prácticas que se saben efectivas, cuidar la salud de los trabajadores, aplicar la evidencia y colaborar con su construcción a través del reporte de datos, y siempre aplicar los mismos principios éticos para el cuidado de los niños y las madres con COVID-19 y sin ella". (Sola, Rodríguez, Cardetti, \& Dávila, 2020)

Los esfuerzos apuntan a la prevención de contagio y la atención a las poblaciones vulnerables, en este caso las madres gestantes. Las complicaciones asociadas al COVID-19 principalmente se deben a un desajuste emocional y con ello a la incertidumbre de los posibles efectos sobre su embarazo que tengan los tratamiento probados que combaten la sintomatología moderada o severa a consecuencia del contagio con el SARS-Cov-2.

Ante la amenaza de una enfermedad transmisible, como sucede con la actual pandemia, es imperativo el cuidado de poblaciones vulnerables y especialmente susceptibles, como el grupo de mujeres gestantes. Aunque la mayoría de las infecciones por coronavirus humanos son leves, las epidemias de coronavirus por SARSCoV y MERS-CoV fueron en especial graves y alrededor de un tercio de las mujeres embarazadas infectadas murieron. Si se tiene en cuenta que el SARS-CoV-2 parece tener similar potencial de contagio que el SARS-CoV y el MERS-CoV, las mujeres embarazadas están en mayor riesgo de infecciones graves y no se han identificado signos clínicos específicos que precedan a las complicaciones graves (Berumen Lechuga, Leaños Miranda, \& Molina Pérez, 2020, pág. 2).

Las alteraciones fisiológicas inmunológicas que se dan durante el embarazo nos lleva a suponer que es un grupo con alta predisposición a contraer enfermedades virales entre ellas SARS COV 2; alto riesgo de desarrollar de complicaciones obstétricas y perinatales y cuadro respiratorio más grave, hospitalización, morbimortalidad e ingreso a $\mathrm{UCl}$ a diferencia de la población en general. (Pinares Valderrama, 2021)

Pediatras, neonatólogos y enfermeras neonatales no debemos distraer nuestros esfuerzos de los cuidados humanizados, ya que esto puede tener un impacto negativo grave sobre el bienestar perinatal y la vida futura de las personas. Afortunadamente, la información preliminar de las instituciones que reportaron los datos de las 86 mujeres embarazadas con COVID-19 y sus RN es muy alentadora. Es de desear que esto siga mejorando y que todo el equipo de salud reflexione sobre la necesidad de defender el cuidado humanizado y centrado en la familia más allá de la crisis sanitaria y social que vivimos. (Sola, Rodríguez, Cardetti, \& Dávila, 2020)

Los ginecólogos deben desarrollar dentro de su práctica estrategias para abordar la preocupación y la angustia relacionadas con la salud mental en este tiempo de pandemia. Dentro de las implicaciones para la práctica de la salud pública, las mujeres embarazadas y sus familias deben ser asesoradas sobre las medidas para prevenir la infección con el SARS-CoV-2, así como el riesgo potencial de enfermedad grave asociada al COVID-19, incluyendo la muerte. (Pacheco Romero, 2021)

El efecto del COVID-19 sobre los recién nacidos aún están en estudio sin embargo algunas investigaciones reportan que la enfermedad de COVID no influyo en su edad gestación, en el tipo de parto, el puntaje APGAR ni la lactancia materna. Entonces concluyen que la enfermedad no puede ser asociada a mortalidad por perinatal. Las complicaciones evidenciadas no está asociado a COVID sino a factores de ries-

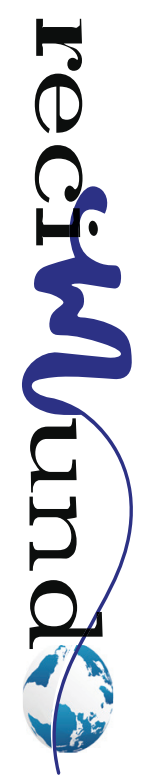


go que presento la madre o factores propios de recién nacido. (Pinares Valderrama, 2021, pág. 3).

Respecto a ello, también se destaca que las investigaciones reconocen las limitaciones para identificar las consecuencias del COVID-19 en la mortalidad infantil. Esto también radica en los ineficientes protocolos de estudios con los que cuenta la ciencia medica para registrar y describir las causas de la mortalidad perinatal. La misma UNESCO y la OMS lo reconocen. La mayoría de los nonatos ni siquiera son registrados en los centros de salud y es una realidad mundial.

Sin embargo, hasta ahora las investigaciones apuntan a que se debe garantizar la inmunización a los recién nacidos dentro de las primeras 12 horas de vida según el esquema nacional de vacunación tanto para tuberculosis (BCG), como hepatitis $B$ (HVB). Si la madre es COVID-19 positiva y HvB positiva se procederá a la inmunización para HvB y la administración de inmunoglobulina específica para HvB en las primeras 12 horas de vida según el protocolo estándar del manejo del hijo de madre portadora de HvB. (Dávila Aliaga, Torres Marcos, Hinojosa Perez, \& Espinoza Vivas, 2020)

\section{Bibliografía}

Aliaga, C. R., Marcos, E., Perez, J., \& Vivas, Y. (2020). Recomendaciones para la atención de recién nacidos hijos de madre COVID-19 positivas. Revista Peruana de Investigación Materno Perinatal, 9(3), 35-39.

Berumen Lechuga, M., Leaños Miranda, A., \& Molina Pérez, C. (2020). Enfermedad por COVID-19 durante el embarazo: una narrativa. Rev Med Inst Mex Seguro Soc.
Dávila Aliaga, C., Hinojosa Pérez, R., Espinola Sánchez, M., Torres Marcos, E., Guevara Ríos, E., Espinoza Vivas, Y., . . . Saldaña Díaz, C. (2021). Resultados materno-perinatales en gestantes con COVID-19 en un hospital nivel III del Perú. Revista Peru Med Exp Salud Pública, 38(1), 58-63.

Dávila Aliaga, C., Torres Marcos, E., Hinojosa Perez, J., \& Espinoza Vivas, Y. (2020). RECOMENDACIONES PARA LA ATENCIÓN DE RECIEN NACIDOS HIJOS DE MADRE COVID-19 POSITIVAS. Revista Peruana de Investigación Materna Perinatal, 3539.

Limay Ríos, O., Dávila Aliaga, C., Álvarez Carrasco, R., \& Espinola Sánchez, M. (2020). Transmisión perinatal de SARS-CoV-2: necesidad de estudio ante posible infección congénita. Revista Colombiana de Obstetricia y Ginecología, 71(3), $297-$ 299.

Organización Mundial de la Salud. (2017). Para que cada bebé cuente: auditoría y examen de las muertes prenatales y neonatales. Geneva: WHO Document Production Services.

Pacheco Romero, J. (2020). La incógnita del coronavirus, la gestante, su niño-Continuación. Revista Peruana de Ginecología y Obstetricia, 66(3).

Pacheco Romero, J. (2021). La incógnita del coronavirus-Variantes y vacunas-La gestante y su niño. Revista Peruana de Ginecología y Obstetricia, $67(1)$

Pinares Valderrama, M. P. (2021). Impacto clínico y epidemiológico de la infección por COVID 19 en gestantes y recién nacidos en un hospital de Cusco 2020-2021.

Sola, A., Rodríguez, S., Cardetti, M., \& Dávila, C. (2020). COVID-19 perinatal en América Latina. Rev Panam Salud Publica, 44e:47.

WHO/MCA/OMS. (2020). Poner fin a las muertes neonatales y fetales prevenibles para 2030. UNICEF/UN. 


\section{CITAR ESTE ARTICULO:}

Grijalva Grijalva, I. O., Marengo Gallardo, H. M., Parreño Grijalva, D. I., \& Bulgarín Sánchez, R. M. (2021). Transmisión perinatal por COVID-19 en América Latina. RECIMUNDO, 5(4), 84-95. https://doi.org/10.26820/recimundo/5.(4). oct.2021.84-95 